䈕 Springer Link

\title{
Global Encyclopedia of Public Administration, Public Policy, and Governance
}

Living Edition

| Editors: Ali Farazmand

\section{Introduction}

This work serves as a comprehensive collection of global scholarship regarding the vast fields of public administration and public policy. Written and edited by leading international scholars and practitioners, this exhaustive resource covers all areas of the twin fields of study. In keeping with the multidisciplinary spirit of these fields, the entries make use of various theoretical, empirical, analytical, practical, and methodological bases of knowledge. The encyclopedia provides a snapshot of the most current research in public administration and public policy, covering such important areas as: 1 . organization theory, behavior, change and development $2 . \quad$ administrative theory and practice 3. bureaucracy 4. public budgeting and financial management 5. public finance and public management $6 . \quad$ public personnel and labor-management relations 7. crisis and emergency management 8. institutional theory and public administration 9. law and regulations 10. ethics and accountability Relevant to professionals, experts, scholars, general readers, and students worldwide, this work will serve as the most viable global reference source for those looking for an introduction to the field.

- $3 \underline{8 \text { Citations }}$

- 151 Mentions

- $3 \mathrm{k}$ Readers

- 19ok Downloads

\section{Editors and affiliations}

- Ali Farazmand (1)

1. Florida Atlantic University, , Boca Raton, USA

\section{Bibliographic information}

- Copyright Information Springer Nature Switzerland AG 2019

- Publisher Name Springer, Cham

- Online ISBN 978-3-319-31816-5

- eBook Packages Economics and Finance

- Number Of Entries 1400 


\section{SPRINGER NATURE}

(C) 2018 Springer Nature Switzerland AG. Part of Sppringer Nature.

Not logged in International Islamic University Malaysia (IIUM) (2000621865) - 4972 SpringerLink Malaysia eBook Consortium-2009-2010 copyright (3000134874) - 6816 SpringerLink Malaysia eJournal Consortium - Higher Education (3000155375) - 8354 Springerlink Malaysia consortium (3000519906) - 10122 SpringerLink Malaysia eJourna Consortium - Higher Education (3000716851) - SpringerLink Malaysia eJournal Consortium - Higher Education (3000916360) 210.48.222.9 